\title{
CONTENTS OF VOLUME 22
}

547. The Lovibond Color System. I. A Spectrophotometric Analysis of the Lovibond Glasses. With a Prefatory Statement By IRWin G. Priest ............ Gibson and $F$. K. Harris

548. Wave-Length Measurements in the Arc and Spark Spectra of Zirconium

549. Wave-Length Measurements in the Arc Spectrum of Scandium William F. Meggers

550. Application of the Algebraic Aberration Equations to Optical Design... . . . . Gardner

551. Absorption Spectra of Iron, Cobalt, and Nickel.

W. F. Meggers and F. M. Walters, jr. 205

552. Transmission of Sound Throdgh Building Materials.

V. L. Chrisler

553. Further Radiometric Measurements and Temperature Estimates of the Planet Mars, 1926.

W. W. Coblentz and C. O. Lampland

554. Determination of Sulphur Trioxide in the Presence of Sulphur Dioxide, Together With Some Analyses of Commercial Liquid SUlphor Dioxide

555. A Weight Burette for the Micromeasurement of Liquid

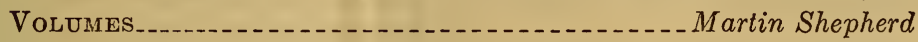

556. Current Distribution in Supraconductors .........F. B. Silsbee

557. A Suggested New Base Point on the Thermometric Scale and THE $\alpha \rightleftarrows \beta$ INVERSION OF QUARTZ.

Frederick Bates and Francis P. Phelps

558. An Analysis of the Arc and Spark Spectra of Scandium (Sc I and Sc II) _._._._._._Henry Norris Russell and William F. Meggers

559. A Burette for the Accurate Measurement of Gas Volumes Without Gas Connection to a Compensator.

E. R. Weaver and Martin Shepherd

560. Density and Electrical Properties of the System, RubberSULPHUR:

Part I. Density of Rubber-Sulphur Compotnds.

A. T. McPherson

Part II. Electrical Properties of Rubber-Sulphur Compoundos_._._H. L. Curtis, A. T. McPherson, and A. H. Scott

561. Cooperative Measurements of Radio Fading in 1925.

J. H. Dellinger, C. B. Jolliffe, and T. Parkinson

562. Density of Hot-Rolled and Heat-Treated Carbon Steels.

H. C. Cross and E. E. Hill

563. Gases in Metals. III. The Determination of Nitrogen in Metals by Fusion in VacuUm.

Louis Jordan and James R. Eckman

564. Absolute Measurement of Capacitance by Maxwell's Method. Harvey L. Curtis and Charles Moon 
565. Thermal Expansion of Beryllium and Alumindm-Beryllium Alloys ... . . . . . . . . Peter Hidnert and W. T. Sweeney

566. Indeterminateness of Eluetrical Charge....... Chester Snow 567. Some Principles Governing the Choice and Utilization of Permanent-Magnet Steels._..._._._._Raymond L. Sanford 568. Methods, Formulas, and Tables for the Calculation of Antenna Capacity .................. Frover 569. Generator for Audio Currents of Adjustable Frequency with Piezo-Electric Stabilization _............. A ugust Hund 570. Thermal Expansion of Alloys of the "Stainless Iron" Trpe. Peter Hidnert and W. T. Sweeney 571. Unusual Features in the Microstructure of Ferrite. Henry S. Rawdon and Torkel Berglund Page 533 547 557 569 631 639 572. Caude and Removal of Certain Heterogeneities in Glass. 